\section{Original Article}

Korean J Transplant 2021;35:161-167 https://doi.org/10.4285/kjt.21.0015
Received August 9, 2021

Revised August 30, 2021

Accepted August 31, 2021

Corresponding author: Shin Hwang Department of Surgery, Asan Medical Center, University of Ulsan College of Medicine, 88 Olympic-ro 43-gil, Songpagu, Seoul 05505, Korea

Tel: +82-2-3010-3930

Fax: +82-2-3010-6701

E-mail: shwang@amc.seoul.kr

(c) The Korean Society for Transplantation This is an Open Access article distributed under the terms of the Creative Commons Attribution Non-Commercial License (http://creativecommons.org/licenses/ by-nc/4.0/) which permits unrestricted non-commercial use, distribution, and reproduction in any medium, provided the original work is properly cited.

\section{$\mathrm{KJT}^{\mathrm{K}}$ \\ KOREAN JOURNAL OF TRANSPLANTATION}

pISSN 2671-8790

eISSN 2671-8804

\title{
Use of minor donors for living donor liver transplantation and associated ethical issues
}

\author{
Shin Hwang, Gi-Won Song, Dong-Hwan Jung, Tae-Yong Ha, Gil-Chun Park, \\ Chul-Soo Ahn, Deok-Bog Moon, Sung-Gyu Lee
}

Division of Hepatobiliary Surgery and Liver Transplantation, Department of Surgery, Asan Medical Center, University of Ulsan College of Medicine, Seoul, Korea

Background: Living liver donation by minors is regarded as justifiable only if minors possess the capacity to consent to donation and the procedure is in their best interests. This study analyzed the incidence of and reasons for living donor liver transplantation (LDLT) by minor donors in Korea, and discussed ethical issues regarding liver donation by minors.

Methods: The databases of the Korean Network for Organ Sharing (KONOS) and Asan Medical Center (AMC) from 2010 to 2019 were retrospectively reviewed to determine the incidence of LDLT by minor donors.

Results: From 2010 to 2019, 590 (4.1\%) of 14,243 liver donors in the KONOS database and 276 (7.5\%) of 3,401 liver donors in the AMC database were minors. The proportions of minor donors in the KONOS and AMC databases were highest in 2012, at $4.1 \%$ and $12.6 \%$, respectively, and lowest in 2019, at $1.1 \%$ and $3.0 \%$, respectively. Because most LDLT recipients had relatively low model for end-stage liver disease scores and hepatocellular carcinoma, they were unlikely candidates for deceased-donor liver transplantation and were highly likely to drop out of LDLT if they waited for 1-2 years. The donor-recipient relationship of minor donors in the AMC database was first-degree in 256 (92.8\%) and second- or third-degree in 20 (7.2\%).

Conclusions: Liver donation by minors is limitedly acceptable only when the minor proves informed, well-considered, and autonomous consent to the procedure and the procedure is in the minor's best interests. We suggest that minors be allowed to donate only to first-degree family members.

Keywords: Donor age; Adolescent; Donor shortage; Hepatocellular carcinoma; Coercion

\section{INTRODUCTION}

Living donor liver transplantation (LDLT) is regarded as a definitive but second-line treatment for patients with endstage liver disease when deceased donors are unavailable. Donation from living donors has raised various ethical, psychosocial, and medical issues because donation requires sacrifice by living individuals. Autonomous consent to do- nation by adults is acceptable, but donation by minors has various ethical and psychosocial limitations. Kidney donation by minor family members has been rarely performed in Korea because renal replacement therapy allows most recipient candidates to wait for several years until the potential minor donors reach adulthood. By contrast, delay of donation for prolonged periods of time in LDLT candidates is often not feasible, as patient conditions often worsen 


\section{HIGHLIGHTS}

- Liver donation by minors is limitedly acceptable only when the minor proves informed, well-considered, and autonomous consent to the procedure and the procedure is in the minor's best interests.

- We suggest that minors be allowed to donate only to first-degree family members.

rapidly, or hepatocellular carcinoma (HCC) progresses due to unfavorable treatment responses. Thus, some minors who may be the only suitable candidates for liver donation are willing to donate their liver to save the lives of closely related recipients. It is accepted that living liver donation by minors is regarded as justifiable only if minors possess the capacity to consent to donation and the procedure is in their best interests [1].

The present study analyzed the actual incidence of and reasons for LDLT by minor donors, as well as we discussed the ethical and psychosocial issues associated with liver donation by minors.

\section{METHODS}

The study protocol was approved by the Institutional Review Board of the Asan Medical Center (AMC; IRB No. 2020-0856), which waived the requirement for informed consent due to the retrospective nature of this study. This study was performed in accordance with the ethical guidelines of the World Medical Association Declaration of Helsinki 2013.

\section{Study Design}

The databases of the Korean Network for Organ Sharing (KONOS) and AMC during the 10-year period from January 2010 to December 2019 were retrospectively reviewed to determine the incidence of LDLT with minor donors. By law in Korea, minors can donate organs if they are aged 16-18 years and the recipients are in the firstto third-degree kinship. The background reasons for donations by minors were reviewed in detail.

\section{RESULTS}

\section{Percentage of Minor Living Donors in the KONOS Database}

During the 10-year study period, 20,586 living individuals donated solid organs for transplantation in Korea; their age distribution is depicted in Fig. 1. Of these living donors, $606(2.9 \%)$ were aged $16-18$ years (Table 1 ).

\section{Percentages of Minor Living Donors for Kidney Transplantation in the KONOS and AMC Databases}

During this 10-year period, 17,073 individuals in the KONOS database and 2,516 in the AMC database were living kidney donors for transplantation. Of these, 68 minors $(0.4 \%)$

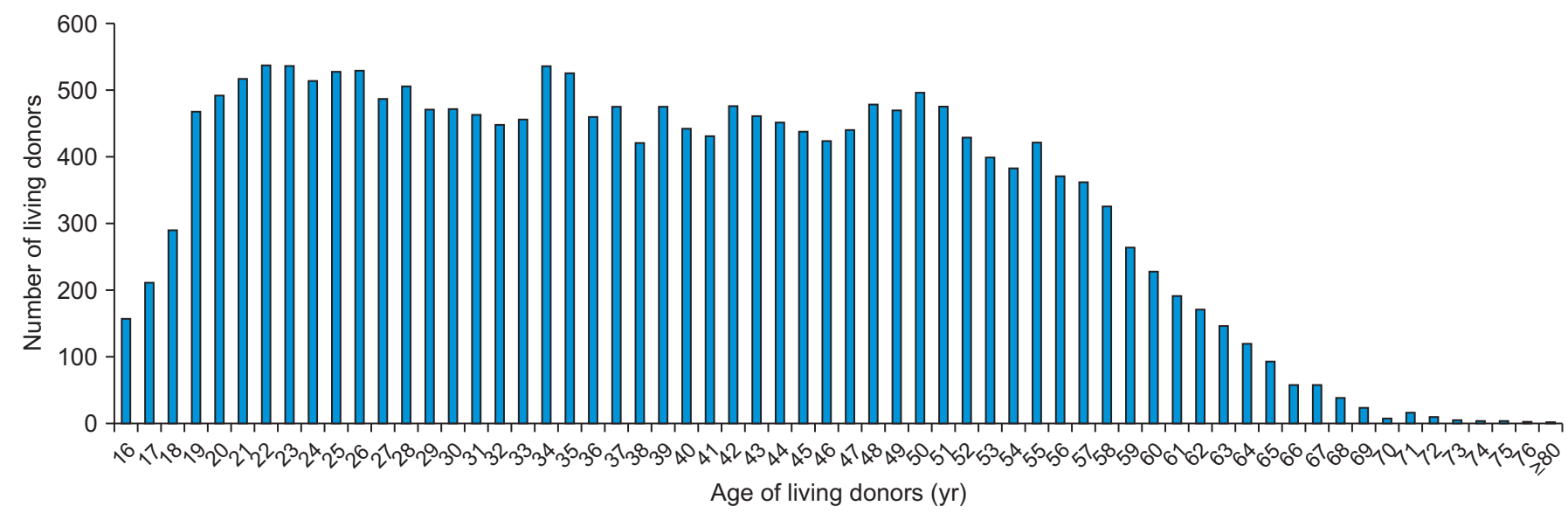

Fig. 1. Age distribution of all living solid organ transplant donors from January 2010 to December 2019 in Korea. 
Hwang S et al. Minor donors for living donor liver transplantation

Table 1. Annual numbers of minor living donors for solid organ transplantation in Korea

\begin{tabular}{|c|c|c|c|c|c|c|c|c|c|c|c|c|c|}
\hline Age (yr) & Year & 2010 & 2011 & 2012 & 2013 & 2014 & 2015 & 2016 & 2017 & 2018 & 2019 & Subtotal & Total \\
\hline \multirow[t]{3}{*}{16} & Subtotal & 17 & 26 & 22 & 22 & 13 & 14 & 16 & 16 & 8 & 3 & & 157 \\
\hline & Male & 14 & 19 & 18 & 17 & 9 & 11 & 13 & 13 & 7 & 3 & 124 & \\
\hline & Female & 3 & 7 & 4 & 5 & 4 & 3 & 3 & 3 & 1 & 0 & 33 & \\
\hline \multirow[t]{3}{*}{17} & Subtotal & 27 & 21 & 26 & 28 & 23 & 18 & 21 & 17 & 16 & 14 & & 211 \\
\hline & Male & 19 & 20 & 18 & 20 & 15 & 14 & 18 & 14 & 11 & 10 & 159 & \\
\hline & Female & 8 & 1 & 8 & 8 & 8 & 4 & 3 & 3 & 5 & 4 & 52 & \\
\hline \multirow[t]{3}{*}{18} & Subtotal & 35 & 35 & 43 & 29 & 22 & 30 & 25 & 36 & 23 & 12 & & 290 \\
\hline & Male & 28 & 27 & 36 & 23 & 16 & 22 & 16 & 28 & 18 & 9 & 223 & \\
\hline & Female & 7 & 8 & 7 & 6 & 6 & 8 & 9 & 8 & 5 & 3 & 67 & \\
\hline Subtotal & & 71 & 81 & 83 & 71 & 50 & 58 & 59 & 66 & 42 & 25 & 606 & 606 \\
\hline
\end{tabular}

Table 2. Annual numbers of minor living donors for liver transplantation in Korea

\begin{tabular}{|c|c|c|c|c|c|c|}
\hline \multirow{2}{*}{ Year } & \multirow{2}{*}{ Korea } & \multicolumn{4}{|c|}{ Asan Medical Center } & \multirow{2}{*}{ Proportion $^{\mathrm{a})}(\%$} \\
\hline & & $16 \mathrm{yr}$ & $17 \mathrm{yr}$ & $18 \mathrm{yr}$ & Subtotal & \\
\hline 2010 & 71 & 9 & 9 & 10 & 28 & 39.4 \\
\hline 2011 & 71 & 10 & 6 & 12 & 28 & 39.4 \\
\hline 2012 & 79 & 10 & 16 & 17 & 43 & 54.4 \\
\hline 2013 & 73 & 11 & 14 & 10 & 35 & 47.9 \\
\hline 2014 & 49 & 5 & 11 & 10 & 26 & 53.1 \\
\hline 2015 & 59 & 6 & 7 & 11 & 24 & 40.7 \\
\hline 2016 & 57 & 7 & 8 & 10 & 25 & 43.9 \\
\hline 2017 & 62 & 11 & 8 & 20 & 39 & 62.9 \\
\hline 2018 & 40 & 5 & 4 & 5 & 14 & 35.0 \\
\hline 2019 & 29 & 1 & 8 & 5 & 14 & 48.3 \\
\hline Total & 590 & 75 & 91 & 110 & 276 & 46.8 \\
\hline
\end{tabular}

a) Ratio of the number of minor donors in the Asan Medical Center database to those in the nationwide Korean Network for Organ Sharing database.

in the KONOS database and $13(0.5 \%)$ in the AMC database were living kidney donors for transplantation (Supplementary Table 1).

\section{Percentages of Minor Living Donors for Liver Transplantation in the KONOS and AMC Databases}

During the same 10 -year period, 14,243 persons in the KONOS database and 3,662 in the AMC database were donors for LDLT. Of these subjects, 590 (4.1\%) in the KONOS database and $276(7.5 \%)$ in the AMC database were aged 16-18 years (Table 2). The annual proportions of minor donors for LDLT in the KONOS and AMC databases are depicted in Fig. 2. The proportion of minor donors to all-age donors peaked in 2012 , at $4.1 \%$ in the KONOS database and $12.6 \%$ in the AMC database, and were lowest in 2019 , at $1.1 \%$ and $3.0 \%$, respectively.

\section{Reasons for Minor Donor Selection for LDLT at AMC in 2017}

During the year of 2017, 39 donors donated livers for LDLT. Of the 11 donors aged 16 years, nine were sons and two were daughters (including one dual-graft donor) of the recipients. Their median height and body weight were 175.8 $\mathrm{cm}$ and $69.1 \mathrm{~kg}$, respectively. The recipients included nine fathers and two mothers, of median age 48 years (range, 41-57 years). Their median model for end-stage liver disease (MELD) score was 15 (range, 9-19). Nine recipients had hepatitis $B$ virus (HBV)-associated liver cirrhosis (LC), one had idiopathic LC, and one had alcoholic liver disease. Nine recipients (81.8\%) had HCC. Four recipients had waited to undergo LDLT until their donors reached 16 years of age.

Of the eight donors aged 17 years, four were sons, two were daughters, and two were nephews (including one dual-graft donor) of the recipients. Their median height and 
body weight were $171.5 \mathrm{~cm}$ and $72.8 \mathrm{~kg}$, respectively. The recipients included five fathers, one mother, one aunt, and one uncle, of median age 49 years (range, 41-53 years) and median MELD score 18 (range, 10-24). Six recipients had HBV-LC, one had hepatitis $\mathrm{C}$ virus (HCV)-associated LC, and one had alcoholic liver disease. Five recipients (62.5\%) had HCC.

In the 20 donors aged 18 years, 17 were sons, two were

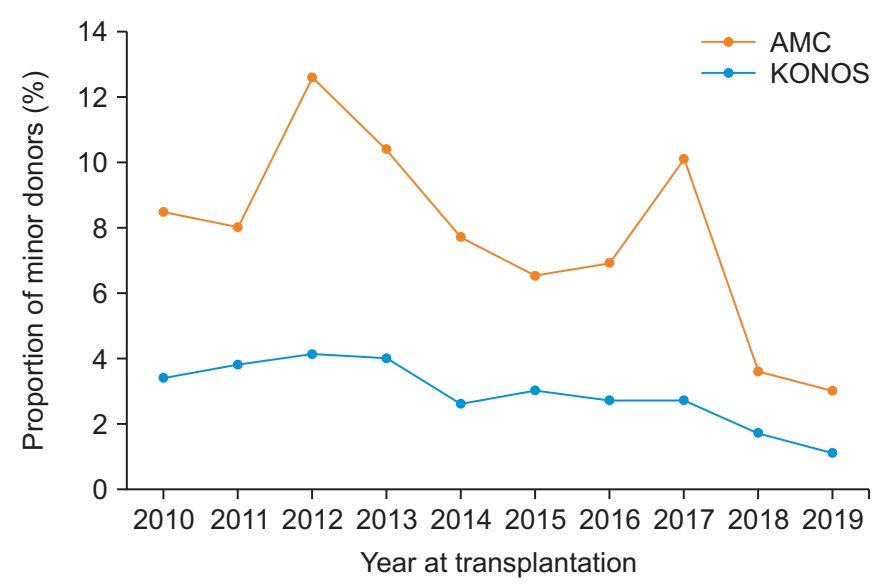

Fig. 2. Annual proportions of minor donors to all living solid organ transplant donors in the Korean Network for Organ Sharing (KONOS) database and Asan Medical Center (AMC) database during 2010-2019. daughters, and one was a nephew of the recipient. Their median height and body weight were $171.4 \mathrm{~cm}$ and 67.9 $\mathrm{kg}$, respectively. The recipients included 17 fathers, two mothers, and one uncle, of median age 49 years (range, 40-56 years) and median MELD score 17 (range, 7-25). Sixteen recipients had HBV-LC, two had alcoholic liver disease, one had HCV-LC, and one had fulminant hepatic failure. Eleven of these recipients (55.0\%) had HCC.

Because their MELD scores were relatively low, most of the recipients were unlikely candidates for deceased donor liver transplantation (DDLT) in the Korean setting with profound organ shortage and MELD score-based liver allocation system. Based on the degree of LC and the advanced

Table 3. Relationships between living donor liver transplantation recipients and minor living donors in the Asan Medical Center database $(n=276)$

\begin{tabular}{llcc}
\hline \multicolumn{1}{c}{ Relationship } & Degree of relationship & Number & Proportion (\%) \\
\hline Parent & First degree & 252 & 91.3 \\
Sibling & First degree & 4 & 1.5 \\
Uncle & Second degree & 8 & 2.9 \\
Aunt & Second degree & 6 & 2.2 \\
Uncle-in-law & Second degree & 2 & 0.7 \\
Grandmother & Second degree & 1 & 0.4 \\
First cousin & Third degree & 3 & 1.1 \\
\hline
\end{tabular}

A

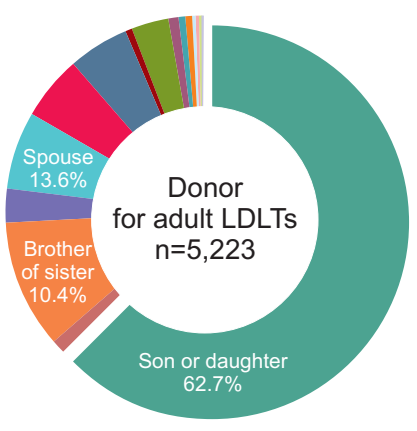

B

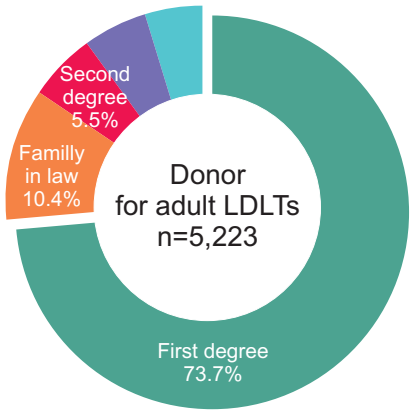

Son or daughter $(n=3,275 / 62.7 \%)$

Son or daughter in law $(n=65 / 1.2 \%)$

Brother or sister $(n=543 / 10.4 \%)$

Brother or sister in law $(n=144 / 2.8 \%)$

Spouse $(n=339 / 6.5 \%)$

$\square$ Nephew or niece $(n=270 / 5.2 \%)$

$\square$ Cousin $(n=265 / 5.1 \%)$

$\square$ Cousin in law $(n=24 / 0.5 \%)$
Friend

$(n=160 / 3.1 \%)$

Volunteer (non-directed) $(n=36 / 0.7 \%)$

Parent

$(n=31 / 0.6 \%)$

Donor exchange $(n=30 / 0.5 \%)$

Other relatives $(n=22 / 0.4 \%)$

$\square$ Uncle or aunt $(n=13 / 0.2 \%)$

Grandchild

$(n=4 / 0.1 \%)$

Grandparent $(n=1 / 0.1 \%)$
Fig. 3. Relationships between living donors and recipients in the first 5,000 cases of adult living donor liver transplantation (LDLT); because of dual-graft donors, the actual number of donors was 5,223. (A) Overall relationships. (B) Degrees of kinship. 
extent of HCC, $60 \%-70 \%$ of HCC patients would drop out of LDLT after waiting for 1 year, and $70 \%-90 \%$ drop out after waiting for 2-3 years because of patient mortality or HCC progression beyond the selection criteria for liver transplantation.

\section{Selection of Minor Donors for LDLT Recipients Other than Their Parents and Siblings at AMC}

The relationship of the 276 minor living donors at AMC to the recipients is summarized in Table 3. Of these donors, $256(92.8 \%)$ were first-degree relatives of the recipients, being children or siblings of the latter, whereas 20 (7.2\%) were second- or third-degree relatives. During 2018 and 2019 , no minor donated to second- or third-degree relative patients.

\section{International LDLT with Minor Donors at AMC}

Of the 276 minor LDLT donors, seven (2.5\%) were from the Middle East, Southeast Asia, or Mongolia. These donors included two 17-year-old sons, one 17-year-old daughter (dual-graft donor), and four 18-year-old sons. KONOS criteria for liver donation by these donors were identical to those for Korean citizens.

\section{Analysis of the Relationship between Donors and Recipients in the First 5,000 Adult LDLTs at AMC}

The donor-recipient relationship of the first 5,000 adult LDLTs at AMC are summarized in Fig. 3A. Of these, 73.7\% donated to first-degree relatives, $11.0 \%$ to in-laws, $5.5 \%$ to second-degree relatives, $5.1 \%$ to third-degree relatives, and $4.7 \%$ to others. The most common donors were, in order, children, siblings, and spouses (Fig. 3B).

\section{DISCUSSION}

During the 10-year period from 2010 to $2019,4.1 \%$ and $7.5 \%$ of LDLT donors in the Korean nationwide KONOS and AMC databases, respectively, were minors. Although the proportions of minor donors have been gradually decreasing over time, they still constitute a considerable portion of living liver donors, primarily because further waiting would result in high waiting-list mortality rates and high drop-out rates from LDLT.

The body sizes of the minor donors aged 16-18 years were quite comparable to those of adults. Because minors with adult body dimension were intentionally chosen as
LDLT donors, their incidence of postoperative complications was similar to that of young adult donors [2-4]. None of the 276 minor liver donors at AMC experienced major surgical complications, indicating that donor safety was not a major concern in the present study.

The main issues in the present study were the legal and moral framework regarding organ donation by minors. Minors are legally regarded as lacking the full capacity to make fully informed medical decisions. However, several studies suggest that minors aged $>14$ years demonstrate a level of cognitive maturity similar to that of adults, possessing adult-like capacities for logical reasoning about moral, social, and interpersonal matters $[5,6]$. Although minors display cognitive capacities close to those of adults, they do not exhibit adult-like levels of psychosocial maturity.

Four psychosocial factors are specifically relevant to decision-making outcomes in minors [7-11]. The first is susceptibility to social coercion, in that minors have been shown to be more susceptible to coercive influences than adults [8]. The second factor is risk perception. In comparison with adults, minors place less weight on risk in relation to reward, and they often consider themselves invulnerable to harm [9]. The third is future orientation, or the extent to which an individual anticipates future consequences. Minors tend to focus mainly on the short-term consequences of their choices, whereas adults also consider long-term effects [10]. The fourth factor is impulsivity, in that minors are prone to more extreme mood swings, and have more difficulty in controlling their impulses and behavior [11]. The established cognitive maturity of minors suggests that they be regarded as having sufficient decisional capacity to make health care decisions that are generally not strongly influenced by any of the aforementioned psychosocial factors. By contrast, their psychosocial immaturity suggests that they be considered as lacking the decisional capacity to make health care decisions with a strong psychosocial component, including decisions that typically elicit impulsivity and involve high levels of social coercion or significant immediate risks/long-term consequences [1].

To determine whether minors have the capacity to consent to living liver donation, it is necessary to identify the type of decision-making process involved. Therefore, it is necessary to examine the extent to which each of the abovementioned psychosocial factors is relevant to the context of living liver donation by minors. As required by KONOS regulations, all minor donors in Korea are thoroughly assessed by psychiatrists and social workers who 
specialize in living donor organ transplantation.

The context of living organ donation exhibits certain features that increase the chances of coercive coercion. One such feature is that donation typically takes place between family members. In the case of living liver donation, there is the added element of the lack of any substitute therapy. Parents, regardless of whether they themselves or one of their children is in need of a liver, may pressure their minor child into donating. Minors are likely to succumb to such pressure because they are socially dependent on their parents. If the candidate recipient is a sibling, the latter may constitute an additional source of coercion [1]. The psychosocial factor of risk perception and future orientation is also highly relevant to the context of living liver donation by minors. Although the actual risks are very low [2-4], living liver donation is associated with some risks of mortality and morbidity. Although, impulsivity is not often a salient psychosocial feature of a minor's decision to consent to living liver donation, impulsivity may be a factor in exceptional circumstances. For example, a minor may be more impulsive if a parent suffers from acute liver failure and has a life expectancy of less than 1 week without transplantation [1]. Under such time pressure, a minor's impulses may dominate over deliberative, reasoned decision making [1]. Because of their psychosocial immaturity, minors considering living liver donation run the risk of yielding to coercive pressures, and placing too little weight on possible immediate and long-term risks. However, a minor's decisions under circumstances requiring expedited transplantation may not be rasher than considered, such that minors should not be regarded as completely incapable of consenting to living liver donation. Nevertheless, the possibility of donor risk indicates that, ideally, minors should not be considered potential living liver donors. However, as shown in the abovementioned example, saving a parent's life through LDLT may be in the best interest of a potential minor donor. The peak of minor donation in AMC in $\mathbf{2 0 1 2}$ was closely associated with a higher proportion of emergency LDLT, with a very low incidence of deceased donors. The peak in AMC in 2017 was associated with adoption of MELD score in KONOS liver allocation.

This study revealed that $92.8 \%$ of minor donors donated to first-degree family members, including parents and siblings. Because the candidate recipients had a very low chance of being allocated for DDLT in the current Korean setting with low incidence of deceased donors and MELD score-based liver allocation system, timely LDLT would be the only chance for prolonged survival. Considering the customs and emotions of most Korean families, there is a general consensus regarding the acceptability of minor donors, as it is directly related to their best interests.

Unexpectedly, we found that $7.2 \%$ of minor donors donated to second- and third-degree family members, including uncles, aunts, in-laws, and first cousins, and even to a grandmother. According to KONOS regulations and Korean law, minors are permitted to donate up to third-degree kinship. Because donation to these more distant relatives than first-degree kinship does not always appear to be in the best interest of minor donors, we believe it is reasonable to restrict minor donations only to first-degree family members. In early 2018 , we recognized the ethical issues in KONOS regulations permitting minors to donate to second- and third-degree relatives; thereafter, our transplant program has not allowed minors to donate other than to first-degree family members, as well as reduced the incidence of donations by minors as much as possible. Thus, the annual number of liver donations by minors has markedly decreased, especially during the last 2 years. Recent increase in the incidence of deceased donors in Korea also helped to decrease the use of minor donors because the need for urgent LDLT was decreased $[12,13]$.

This study had limitation of note, including its retrospective design, and inclusion of a single-center cohort. A Korea nation-wide collective study is needed to draw out consensus guidelines regarding donation by minors.

In conclusion, donation by minors is limitedly acceptable only when the procedure is the result of informed, well-considered, and autonomous consent by the potential donor as well as being in the minor's best interests. We suggest that minors be allowed to donate only to first-degree family members, and not to the currently permitted second- and third-degree relatives. We think that our suggestion will make a compromise on transition toward not allowing donation by minors within the scope of current law.

\section{ACKNOWLEDGMENTS}

\section{Conflict of Interest}

No potential conflict of interest relevant to this article was reported.

\section{Funding/Support}

This study was supported by research grant from the Kore- 
an Society for Transplantation (2021-00-01008-016).

\section{ORCID}

Shin Hwang

Gi-Won Song

Dong-Hwan Jung

Tae-Yong Ha

Gil-Chun Park

Chul-Soo Ahn

Deok-Bog Moon

Sung-Gyu Lee

\section{Author Contributions}

Conceptualization: SH. Data curation: GWS, DHJ. Formal analysis: SH. Methodology: TYH, GCP, DBM. Project administration: SH, SGL. Visualization: SH. Writing-original draft: $\mathrm{SH}$. Writing-review \& editing: all authors.

\section{Supplementary Materials}

Supplementary materials can be found via https://doi. org/10.4285/kjt.21.0015.

\section{REFERENCES}

1. Capitaine L, Thys K, Van Assche K, Sterckx S, Pennings G. Should minors be considered as potential living liver donors? Liver Transpl 2013;19:649-55.

2. Hwang S, Lee SG, Lee YJ, Sung KB, Park KM, Kim KH, et al. Lessons learned from 1,000 living donor liver transplantations in a single center: how to make living donations safe. Liver Transpl 2006;12:920-7.

3. Lee JG, Lee KW, Kwon CH, Chu CW, Kim BW, Choi DL, et al. Donor safety in living donor liver transplantation: the Korean organ transplantation registry study. Liver Transpl 2017;23:999-1006.
4. Choi SS, Cho SS, Kim SH, Jun IG, Hwang GS, Kim YK. Factors associated with blood transfusion in donor hepatectomy: results from 2344 donors at a large single center. Transplantation 2013;96:1000-7.

5. Weithorn LA, Campbell SB. The competency of children and adolescents to make informed treatment decisions. Child Dev 1982;53:1589-98.

6. Hale S. A global developmental trend in cognitive processing speed. Child Dev 1990;61:653-63.

7. Steinberg L, Cauffman E, Woolard J, Graham S, Banich M. Are adolescents less mature than adults?: minors' access to abortion, the juvenile death penalty, and the alleged APA "flip-flop". Am Psychol 2009;64:583-94.

8. Gardner M, Steinberg L. Peer influence on risk taking, risk preference, and risky decision making in adolescence and adulthood: an experimental study. Dev Psychol 2005;41:625-35.

9. Schlam L, Wood JP. Informed consent to the medical treatment of minors: law and practice. Health Matrix Clevel 2000;10:141-74.

10. Halpern-Felsher BL, Cauffman E. Costs and benefits of a decision: decision-making competence in adolescents and adults. J Appl Dev Psychol 2001;22:257-73.

11. Farrington DP. Developmental and life-course criminology: key theoretical and empirical issues-The 2002 Sutherland Award address. Criminology 2003;41:22155.

12. Ha H, Hong J, Kim I, Lee S, Lee A, Ha T, et al. Deceased donor liver transplantation under the Korean model for end-stage liver disease score-based liver allocation system: 2-year allocation results at a high-volume transplantation center. Korean J Transplant 2019;33:112-7.

13. Min SI, Ahn C, Han DJ, Kim SI, Chung SY, Lee SK, et al. To achieve national self-sufficiency: recent progresses in deceased donation in Korea. Transplantation 2015;99:765-70. 